\title{
A Controlled Trial of Natalizumab for Relapsing Multiple Sclerosis
}

\author{
David H. Miller, M.D., Omar A. Khan, M.D., William A. Sheremata, M.D., \\ Lance D. Blumhardt, M.D., George P.A. Rice, M.D., Michele A. Libonati, M.S., \\ Allison J. Willmer-Hulme, Ph.D., Catherine M. Dalton, M.B., \\ Katherine A. Miszkiel, M.B., and Paul W. O'Connor, M.D., \\ for the International Natalizumab Multiple Sclerosis Trial Group*
}

ABSTRACT

\section{BACKGROUN D}

In patients with multiple sclerosis, inflammatory brain lesions appear to arise from autoimmune responses involving activated lymphocytes and monocytes. The glycoprotein $\alpha_{4}$ integrin is expressed on the surface of these cells and plays a critical part in their adhesion to the vascular endothelium and migration into the parenchyma. Natalizumab is an $\alpha_{4}$ integrin antagonist that reduced the development of brain lesions in experimental models and in a preliminary study of patients with multiple sclerosis.

\section{METHODS}

In a randomized, double-blind trial, we randomly assigned a total of 213 patients with relapsing-remitting or relapsing secondary progressive multiple sclerosis to receive $3 \mathrm{mg}$ of intravenous natalizumab per kilogram of body weight (68 patients), $6 \mathrm{mg}$ per kilogram (74 patients), or placebo (71 patients) every 28 days for 6 months. The primary end point was the number of new brain lesions on monthly gadolinium-enhanced magnetic resonance imaging during the six-month treatment period. Clinical outcomes included relapses and self-reported well-being.

\section{RESULTS}

There were marked reductions in the mean number of new lesions in both natalizumab groups: 9.6 per patient in the placebo group, as compared with 0.7 in the group given $3 \mathrm{mg}$ of natalizumab per kilogram $(\mathrm{P}<0.001)$ and 1.1 in the group given $6 \mathrm{mg}$ of natalizumab per kilogram $(\mathrm{P}<0.001)$. Twenty-seven patients in the placebo group had relapses, as compared with 13 in the group given $3 \mathrm{mg}$ of natalizumab per kilogram $(\mathrm{P}=0.02)$ and 14 in the group given $6 \mathrm{mg}$ of natalizumab per kilogram $(\mathrm{P}=0.02)$. The placebo group reported a slight worsening in well-being (a mean decrease of $1.38 \mathrm{~mm}$ on a $100-\mathrm{mm}$ visual-analogue scale), whereas the natalizumab groups reported an improvement (mean increase of $9.49 \mathrm{~mm}$ in the group given $3 \mathrm{mg}$ of natalizumab per kilogram and $6.21 \mathrm{~mm}$ in the group given $6 \mathrm{mg}$ of natalizumab per kilogram).

\section{CONCLUSIONS}

In a placebo-controlled trial, treatment with natalizumab led to fewer inflammatory brain lesions and fewer relapses over a six-month period in patients with relapsing multiple sclerosis.
From the Institute of Neurology, London (D.H.M., C.M.D., K.A.M.); Wayne State University School of Medicine, Detroit (O.A.K.); the University of Miami School of Medicine, Miami (W.A.S.); University Hospital, Nottingham, United Kingdom (L.D.B.); the London Multiple Sclerosis Clinic, London, Ont., Canada (G.P.A.R.); Elan Pharmaceuticals, San Francisco (M.A.L., A.J.W.-H.); and St. Michael's Hospital, University of Toronto, Toronto (P.W.O.). Address reprint requests to Dr. Miller at the Department of Neuroinflammation, Institute of Neurology, Queen Sq., London WCIN 3BG, United Kingdom, or at d.miller@ion.ucl.ac.uk.

*Members of the International Natalizumab Multiple Sclerosis Trial Group are listed in the Appendix.

N EnglJ Med 2003;348:15-23.

Copyright $\odot 2003$ Massachusetts Medical Society. 
M

ULTIPLE SCLEROSIS IS A LEADING cause of chronic neurologic disability. ${ }^{1}$ Several new therapies have been introduced in the past decade, ${ }^{2-5}$ but additional effective treatments are needed to slow disease progression and reduce disability. The pathological hallmark of multiple sclerosis is multiple foci of inflammation and demyelination within the white matter of the central nervous system. The formation of these lesions may involve lymphocytes and monocytes that gain access to the brain parenchyma from the circulation by first adhering to vascular endothelial cells in regions of inflammation. ${ }^{6}$ The glycoprotein $\alpha_{4} \beta_{1}$ integrin, also known as very late antigen 4 , or VLA-4, is expressed on the surface of lymphocytes and monocytes and is an important mediator of cell adhesion and transendothelial migration, as well as a regulator of immune-cell activation within inflamed tissue. ${ }^{7,8}$

Brain lesions in patients with multiple sclerosis are readily detected with $\mathrm{T}_{2}$-weighted magnetic resonance imaging (MRI). New lesions with features of inflammation can be detected by gadoliniumenhanced $\mathrm{T}_{1}$-weighted MRI, 9-12 and this approach has been used to assess disease activity in clinical trials.

Treatment with an antibody against $\alpha_{4}$ integrin reduced signs of disease activity and inflammation in mice with experimentally induced allergic encephalomyelitis, a rodent model of multiple sclerosis. ${ }^{13-15}$ Natalizumab (Antegren, Elan Pharmaceuticals and Biogen), a humanized monoclonal antibody, is an $\alpha_{4}$ integrin antagonist in a class of agents known as selective adhesion-molecule inhibitors. In a small, placebo-controlled study of patients with multiple sclerosis, natalizumab reduced the frequency of new gadolinium-enhancing lesions. ${ }^{16}$ Because the patients received only two infusions one month apart, the longer-term effects of antagonism of $\alpha_{4}$ integrin on the formation of brain lesions and various clinical outcomes are unknown. Therefore, we conducted a randomized, placebo-controlled trial of six months of treatment with natalizumab in patients with relapsing multiple sclerosis.

\section{METHODS}

\section{PATIENTS}

Twenty-six clinical centers in the United States, Canada, and the United Kingdom enrolled 213 patients from September 1999 until May 2000. The protocol was reviewed and approved by central and local ethics committees. Before providing informed consent, all patients were told by the investigator of the alternative effective therapies available to them, and any who wished to try one of these therapies were encouraged to do so. All patients gave written informed consent. The study was overseen by an independent data and safety monitoring committee. The study data were gathered by the investigators and by an independent organization (PPD Development); the data were held and analyzed by Elan and Biogen. The principal investigators on the writing team had access to all data.

Eligible patients were 18 through 65 years of age, met the criteria of Poser et al. for clinically definite or laboratory-supported definite multiple sclerosis ${ }^{17}$ - either relapsing-remitting or secondary progressive multiple sclerosis ${ }^{18}$ — had had at least two relapses within the previous two years, had a base-line score on the Kurtzke Expanded Disability Status Scale ${ }^{19}$ between 2 and 6.5 (scores can range from 0 to 10, with higher scores indicating more severe disease), and had had a minimum of three lesions on $\mathrm{T}_{2}$-weighted MRI of the brain. Patients were ineligible if they had received immunosuppressive or immunomodulating treatments within the preceding 3 months or had had a relapse or received systemic corticosteroids within the preceding 30 days.

\section{STUDY DESIGN AND RANDOMIZATION}

Patients were randomly assigned to one of three treatments $-3 \mathrm{mg}$ of natalizumab per kilogram of body weight, $6 \mathrm{mg}$ of natalizumab per kilogram, or placebo - with use of a computer-generated block randomization schedule. Randomization was performed centrally by PPD Development. Patients received an intravenous infusion every 28 days for 6 months and were then monitored for an additional 6 months for adverse effects. Neither the study personnel nor the patients were aware of the blinded treatment assignments.

\section{STUDY PROCEDURES AND END POINTS}

Unenhanced proton-density, $\mathrm{T}_{2}$-weighted MRI and gadolinium-enhanced $\mathrm{T}_{1}$-weighted $\mathrm{MRI}$ scans were obtained during the screening phase (one month before randomization), immediately before each treatment (months 0 through 5), and one month after the last treatment (month 6). Follow-up scans were obtained at months 9 and 12. Forty-six contiguous, 3-mm-thick, axial slices were acquired 
through the brain. MRI analysis was performed by a single center whose members were unaware of the patients' treatment and history. Two experienced clinicians identified the lesions on hard-copy images after reaching a consensus.

The primary outcome measure was the number of new gadolinium-enhancing lesions over the sixmonth treatment period, defined as the period following the first infusion (month 1) to one month after the last infusion (month 6). Other MRI outcomes included the number of persistent enhancing lesions (enhancing lesions that had also been present on the previous monthly scan); the volume of enhancing lesions (measured with use of a semiautomated method ${ }^{20}$ ); the number of new active lesions (the number of new enhancing lesions plus the number of new or newly enlarging, nonenhancing lesions on $\mathrm{T}_{2}$-weighted MRI); and the number of scans showing one or more new enhancing lesions.

Secondary and tertiary clinical end points included the frequency of relapse, changes in the scores on the Kurtzke Expanded Disability Status Scale, and patients' own assessments of well-being. All adverse events were recorded. Patients were examined at scheduled intervals - and at unscheduled visits in the case of a suspected relapse - by the treating and evaluating neurologists, both of whom were unaware of the patients' treatment assignments. The treating neurologist obtained a medical history and, at each monthly visit, conducted physical and neurologic examinations and recorded adverse events. The evaluating neurologist assessed each patient's neurologic status at quarterly intervals and at unscheduled visits and assigned each a score on the Expanded Disability Status Scale without knowledge of the patient's history or prior scores.

An objective relapse, determined by the evaluating neurologist, was defined as the occurrence of an acute episode of new or worsening symptoms of multiple sclerosis that lasted at least 48 hours after a stable period of at least 30 days and was accompanied by an increase from base line of at least one point in the score on the Expanded Disability Status Scale, at least one point on two functional system scores, or at least two points on one functional system score. Neurologic symptoms that did not meet the above criteria for relapse but were judged by the treating neurologist to constitute a relapse were also recorded (and included in the total number of relapses).

On a visual-analogue scale, patients marked a point along a $100-\mathrm{mm}$ line that reflected their assessment of overall well-being at base line and after three and six months of treatment. Higher scores reflected a greater sense of well-being.

Serum samples were collected at each visit and analyzed for binding antibodies against natalizumab with use of an enzyme-linked immunosorbent assay. Serum levels of natalizumab and the extent of $\alpha_{4}$ integrin-receptor occupancy by natalizumab were measured in a subgroup of 12 to 14 patients per treatment group before each infusion and 2 hours, 24 hours, and one, two, and three weeks after the first and last infusions. Patients were followed clinically to month 12 . Patients who discontinued treatment prematurely were encouraged to return for follow-up assessments.

\section{STATISTICAL ANALYSIS}

Estimates of sample size were based on the number of new enhancing lesions observed during the first 12 weeks after the first infusion in a previous clinical trial of natalizumab. ${ }^{16}$ Using methods based on the Wilcoxon-Mann-Whitney statistic ${ }^{21}$ appropriate for a two-group comparison at a two-sided level of significance of 5 percent, we calculated that approximately 73 patients were needed in each group for the study to have 80 percent power.

The primary comparison of the number of new enhancing lesions was evaluated with use of the Wilcoxon-Mann-Whitney rank-sum test. Given the short-term effects of corticosteroids on gadoliniumenhancing lesions, MRI scans obtained from patients who had received systemic corticosteroids within the previous 30 days were discarded and treated as missing values to avoid confounding of the efficacy analyses. We imputed these missing values and those due to one or more scans' not being performed by replacing the missing value with the average number of lesions on available scans obtained at months 1 through 6 for that patient. This type of imputation was performed for the primary end point as well as all other end points involving lesion counts during the six-month treatment phase. According to the prespecified analysis, the imputation of lesion volume and scores on the Expanded Disability Status Scale followed the principle of the last observation carried forward. No imputation method was specified for the analyses of relapses at any point during the study and MRI data after month 6 ; therefore, missing data were excluded from these analyses during the corresponding period.

Demographic and base-line clinical characteris- 
tics were compared with use of a two-way analysis of variance, with site and group included as independent variables, for continuous data and Fisher's exact test for categorical data. Base-line MRI characteristics were compared with use of the KruskalWallis test. For analysis of the end points, we used the Wilcoxon-Mann-Whitney rank-sum test for all analyses involving lesion counts, including the primary end point. Averaged scores were assigned to tied rank values. Lesion volumes, the mean percentage of scans showing activity, and changes from base line in the scores for the Expanded Disability Status Scale and visual-analogue scale were analyzed with the use of two-way analysis of variance, with site and group included as independent variables. Fisher's exact test was used to compare the proportions of patients in each group who had one or more relapses. When no data were available to determine whether a relapse could be objectively confirmed, that relapse was excluded from the analysis of objective relapses.

All analyses followed the intention-to-treat principle. All reported P values are two-tailed. No interim analyses were performed before the primary end point was analyzed.

\section{RESULTS}

Among the 213 patients, 71 were randomly assigned to receive placebo, 68 to receive $3 \mathrm{mg}$ of natalizumab per kilogram, and 74 to receive $6 \mathrm{mg}$ of natalizumab per kilogram. There were no significant differences in clinical or MRI characteristics at base line (Table 1).

All the patients received at least one dose of the assigned drug. Five patients in the placebo group, five in the group given $3 \mathrm{mg}$ of natalizumab per kilogram, and eight in the group given $6 \mathrm{mg}$ of natalizumab per kilogram discontinued treatment prematurely. Of these patients, three in the placebo group, four in the 3-mg group, and one in the 6-mg group remained in the study until the end of the treatment period. In the analysis of the primary end point during the treatment period, 6.3 percent of the values were imputed: the distribution of imputed values was 8.2 percent of those in the placebo group, 2.9 percent of those in the 3-mg group, and 7.7 percent of those in the 6-mg group.

\section{PRIMARY OUTCOME}

The placebo group had a mean of 9.6 new gadolinium-enhancing lesions per patient during the treatment period. The corresponding means were 0.7 in the group given $3 \mathrm{mg}$ of natalizumab per kilogram $(\mathrm{P}<0.001)$ and 1.1 in the group given $6 \mathrm{mg}$ of natalizumab per kilogram $(\mathrm{P}<0.001)$ (Table 2 and Fig. 1). There was no significant difference in values between the two natalizumab groups. A sensitivity analysis, performed with and without imputed values (the latter including actual counts on MRI scans obtained within 30 days after corticosteroid treatment), yielded consistent, statistically significant results.

The subgroup of patients with relapsing-remitting multiple sclerosis had significantly fewer new enhancing lesions with either dose of natalizumab than with placebo (mean, 12.1 in the placebo group, as compared with 0.6 in the group given $3 \mathrm{mg}$ of natalizumab per kilogram $[\mathrm{P}<0.001]$ and 0.6 in the group given $6 \mathrm{mg}$ of natalizumab per kilogram $[\mathrm{P}<0.001])$. The subgroup of patients with secondary progressive multiple sclerosis had fewer new enhancing lesions with natalizumab than with placebo, and the difference was statistically significant in the group given $3 \mathrm{mg}$ of natalizumab per kilogram (mean, 5.4 in the placebo group, as compared with 1.0 in the group given $3 \mathrm{mg}$ of natalizumab per kilogram $[\mathrm{P}=0.005]$ and 2.0 in the group given $6 \mathrm{mg}$ of natalizumab per kilogram $[\mathrm{P}=0.08]$ ).

\section{SECONDARY MRI OUTCOMES}

There was a marked reduction in the number of persistent enhancing lesions, the number of new active lesions, the total volume of enhancing lesions, and the percentage of scans showing activity in each natalizumab group as compared with the placebo group (Table 2).

\section{CLINICAL OUTCOMES}

During the six-month treatment period, 36 relapses were reported in 27 of the 71 patients in the placebo group (38 percent), as compared with 18 in 13 of the 68 patients receiving $3 \mathrm{mg}$ of natalizumab per kilogram (19 percent, $\mathrm{P}=0.02$ ) and 15 in 14 of the 74 patients receiving $6 \mathrm{mg}$ of natalizumab per kilogram (19 percent, $\mathrm{P}=0.02$ ). Using the objective criteria, we identified 18 relapses in 15 patients in the placebo group (21 percent), as compared with 3 in 3 patients receiving $3 \mathrm{mg}$ of natalizumab per kilogram (4 percent, $\mathrm{P}=0.004$ ) and 8 in 8 patients receiving $6 \mathrm{mg}$ of natalizumab per kilogram (11 percent, $\mathrm{P}=0.11$ ). Sensitivity analyses were performed in which patients with data missing were counted as either having had a relapse or not having had a relapse; all three approaches yielded consistent results. More patients in the placebo group than in 
either of the natalizumab groups received corticosteroid treatment (using the permitted regimen of $1 \mathrm{~g}$ of intravenous methylprednisolone per day for three or five days) for relapse: 22 of 27 (81 percent), as compared with 5 of 13 in the group given $3 \mathrm{mg}$ of natalizumab per kilogram ( 38 percent, $\mathrm{P}<0.001$ ) and 7 of 14 in the group given $6 \mathrm{mg}$ of natalizumab per kilogram ( 50 percent, $\mathrm{P}=0.002$ ) (Table 3 ).

The visual-analogue scores of well-being at month 6 were compared with base-line scores. The placebo group reported a slight worsening (mean decrease of $1.38 \mathrm{~mm}$ on a $100-\mathrm{mm}$ scale), whereas the group given $3 \mathrm{mg}$ of natalizumab per kilogram and that given $6 \mathrm{mg}$ of natalizumab per kilogram reported an improvement (mean increase, $9.49 \mathrm{~mm}$ $[\mathrm{P}=0.04]$ and $6.21 \mathrm{~mm}[\mathrm{P}=0.03]$, respectively). No significant changes in the scores on the Expanded Disability Status Scale were observed in any group during the six-month treatment period (mean increase of 0.03 in the placebo group and mean decrease of 0.14 and 0.03 in 3-mg and 6-mg groups, respectively).

\section{PHARMACODYNAMICS}

Total white-cell counts increased in both natalizumab groups within the first month of treatment and remained elevated until month 7 in the group given $3 \mathrm{mg}$ of natalizumab per kilogram and month 8 in the group given $6 \mathrm{mg}$ of natalizumab per kilogram. There were increases in the lymphocyte, monocyte, and eosinophil counts in both natalizumab groups, but the mean values were not beyond the normal range and returned to base line by month 9. There was no increase in neutrophil counts.

Binding antibodies against natalizumab developed in 15 patients in the natalizumab groups (11 percent) -13 during the treatment period and 2 during the post-treatment follow-up period. Pharmacokinetic analysis showed that serum levels of natalizumab were proportional to the dose given. Patients who received $3 \mathrm{mg}$ of natalizumab per kilogram had more than 80 percent saturation of the $\alpha_{4}$ integrin receptors on peripheral-blood leukocytes during the treatment period; receptor occupancy was approximately 90 percent and was more prolonged in those receiving $6 \mathrm{mg}$ of natalizumab per kilogram.

\section{SAFETY AND TOLERABILITY}

Similar numbers of patients in each group had adverse events during treatment (Table 4). Eleven serious adverse events occurred in seven patients in the placebo group, five serious events occurred in five patients who were receiving $3 \mathrm{mg}$ of natalizumab per kilogram, and four such events occurred in three patients who were receiving $6 \mathrm{mg}$ of natalizumab per kilogram. Four of these events were considered to be immune-mediated and related to the study drug. One patient who was receiving $3 \mathrm{mg}$ of natalizumab per kilogram had an anaphylactoid reaction with urticaria and bronchospasm, which was rapidly reversed with antihistamines and corti-

\begin{tabular}{|c|c|c|c|}
\hline Characteristic & $\begin{array}{l}\text { Placebo } \\
(\mathrm{N}=71)\end{array}$ & $\begin{array}{c}3 \mathrm{mg} \text { of } \\
\text { Natalizu- } \\
\mathrm{mab} / \mathrm{kg} \\
(\mathrm{N}=68)\end{array}$ & $\begin{array}{c}6 \mathrm{mg} \text { of } \\
\text { Natalizu- } \\
\mathrm{mab} / \mathrm{kg} \\
(\mathrm{N}=74)\end{array}$ \\
\hline \multicolumn{4}{|l|}{ Age $-y r$} \\
\hline Mean & 42.9 & 42.8 & 44.9 \\
\hline Range & $22-66$ & $22-65$ & $30-63$ \\
\hline \multicolumn{4}{|l|}{ Sex-no. (\%) } \\
\hline Male & $25(35)$ & $21(31)$ & $15(20)$ \\
\hline Female & $46(65)$ & $47(69)$ & $59(80)$ \\
\hline \multicolumn{4}{|l|}{ Category of multiple sclerosis — no. (\%) } \\
\hline Relapsing-remitting & $45(63)$ & $47(69)$ & $52(70)$ \\
\hline Secondary progressive & $26(37)$ & $21(31)$ & $22(30)$ \\
\hline \multicolumn{4}{|l|}{ Score on Expanded Disability Status Scale’’ } \\
\hline Mean & 4.4 & 4.2 & 4.3 \\
\hline Range & $2.0-6.5$ & $1.0-6.5$ & $0.0-6.5$ \\
\hline \multicolumn{4}{|l|}{ Disease duration $-\mathrm{yr}$} \\
\hline Mean & 10.2 & 11.6 & 13.1 \\
\hline Range & $1-32$ & $0-40$ & $2-39$ \\
\hline \multicolumn{4}{|l|}{ No. of relapses in past $2 \mathrm{yr}$} \\
\hline Mean & 3.0 & 2.9 & 3.1 \\
\hline Range & $2-12$ & $2-10$ & $2-8$ \\
\hline \multicolumn{4}{|l|}{ Time since last relapse - mo } \\
\hline Mean & 6.5 & 7.2 & 6.0 \\
\hline Range & $2-17$ & $2-24$ & $2-22$ \\
\hline \multicolumn{4}{|l|}{ Base-line $\mathrm{T}_{1}$-weighted MRI (month 0) } \\
\hline $\begin{array}{l}\text { Scans with } \geq 1 \text { new gadolinium- } \\
\text { enhancing lesions - no. (\%) }\end{array}$ & $22(31)$ & $29(43)$ & $32(43)$ \\
\hline \multicolumn{4}{|l|}{$\begin{array}{l}\text { No. of new gadolinium-enhancing } \\
\text { brain lesions }\end{array}$} \\
\hline Mean & 1.3 & 1.3 & 1.4 \\
\hline Range & $0-28$ & $0-32$ & $0-12$ \\
\hline \multicolumn{4}{|l|}{ Screening $\mathrm{T}_{1}$-weighted MRI (month -1) } \\
\hline $\begin{array}{c}\text { Scans with } \geq 1 \text { gadolinium-enhancing } \\
\text { lesions - no. (\%) }\end{array}$ & $28(40) \div$ & $29(43)$ & $29(39)$ \\
\hline \multicolumn{4}{|l|}{$\begin{array}{l}\text { No. of gadolinium-enhancing brain } \\
\text { lesions }\end{array}$} \\
\hline Mean & 1.6 & 1.5 & 1.6 \\
\hline Range & $0-42$ & $0-18$ & $0-23$ \\
\hline
\end{tabular}

* There were no significant differences between the groups.

$\dagger$ Scores can range from 0 to 10 ; higher scores indicate more severe disease. $\checkmark \mathrm{MRI}$ scans were not available for one patient. 


\begin{tabular}{|c|c|c|c|c|c|}
\hline \multirow[t]{2}{*}{ Finding } & \multirow[t]{2}{*}{$\begin{array}{l}\text { Placebo } \\
(\mathrm{N}=71)\end{array}$} & \multirow[t]{2}{*}{$\begin{array}{c}3 \mathrm{mg} \text { of } \\
\text { Natalizumab/kg } \\
(\mathrm{N}=68)\end{array}$} & \multirow[t]{2}{*}{$\begin{array}{c}6 \mathrm{mg} \text { of } \\
\text { Natalizumab/kg } \\
(\mathrm{N}=74)\end{array}$} & \multicolumn{2}{|c|}{ P Value } \\
\hline & & & & $\begin{array}{l}\text { Placebo vs. } \\
3 \text { mg of } \\
\text { Natalizumab }\end{array}$ & $\begin{array}{l}\text { Placebo vs. } \\
6 \text { mg of } \\
\text { Natalizumab }\end{array}$ \\
\hline \multicolumn{6}{|l|}{ Treatment } \\
\hline \multicolumn{6}{|c|}{ No. of new enhancing lesions/patient } \\
\hline Mean & 9.6 & 0.7 & 1.1 & $<0.001$ & $<0.001$ \\
\hline Median & 2.0 & 0 & 0 & & \\
\hline \multicolumn{6}{|c|}{ New enhancing lesions - no. of patients (\%) } \\
\hline No lesions & $23(32)$ & $51(75)$ & $48(65)$ & & \\
\hline 1-3 Lesions & $18(25)$ & $14(21)$ & $20(27)$ & & \\
\hline 4-6 Lesions & $13(18)$ & $1(1)$ & $5(7)$ & & \\
\hline 7-9 Lesions & 0 & 0 & 0 & & \\
\hline 10-12 Lesions & $3(4)$ & $1(1)$ & 0 & & \\
\hline$>12$ Lesions & $14(20)$ & $1(1)$ & $1(1)$ & & \\
\hline \multicolumn{6}{|c|}{ No. of persistent enhancing lesions/patient } \\
\hline Mean $\pm S D$ & $3.6 \pm 6.4$ & $0.8 \pm 1.9$ & $1.3 \pm 2.6$ & $<0.001$ & 0.005 \\
\hline Median & 1 & 0 & 0 & & \\
\hline \multicolumn{6}{|c|}{ No. of new active lesions/patient } \\
\hline Mean $\pm S D$ & $9.7 \pm 27.4$ & $0.8 \pm 2.2$ & $1.1 \pm 3.0$ & $<0.001$ & $<0.001$ \\
\hline Median & 2.0 & 0 & 0 & & \\
\hline Scans showing activity — \% & 39 & 9 & 11 & $<0.001$ & $<0.001$ \\
\hline \multicolumn{6}{|c|}{ Volume of enhancing lesions $-\mathrm{mm}^{3}$} \\
\hline Mean $\pm S D$ & $1168.8 \pm 2665.5$ & $156.2 \pm 349.3$ & $278.6 \pm 632.5$ & 0.005 & 0.01 \\
\hline Median & 266.0 & 0 & 0 & & \\
\hline \multicolumn{6}{|l|}{ Follow-up'ì } \\
\hline \multicolumn{6}{|c|}{ No. of new enhancing lesions/patient } \\
\hline Mean $\pm S D$ & $2.4 \pm 4.2$ & $2.5 \pm 4.5$ & $2.3 \pm 5.2$ & 0.89 & 0.98 \\
\hline Median & 1.0 & 1.0 & 1.0 & & \\
\hline \multicolumn{6}{|c|}{ No. of persistent enhancing lesions/patient } \\
\hline Mean $\pm S D$ & $0.2 \pm 0.46$ & $0.1 \pm 0.33$ & $0.1 \pm 0.32$ & 0.17 & 0.09 \\
\hline Median & 0 & 0 & 0 & & \\
\hline \multicolumn{6}{|c|}{ No. of new active lesions/patient } \\
\hline Mean $\pm S D$ & $2.7 \pm 4.3$ & $2.8 \pm 5.7$ & $2.5 \pm 5.3$ & 0.72 & 0.82 \\
\hline Median & 1.0 & 1.0 & 1.0 & & \\
\hline Scans showing activity — \% & 40 & 41 & 36 & 0.96 & 0.35 \\
\hline \multicolumn{6}{|c|}{ Volume of enhancing lesions $-\mathrm{mm}^{3}$} \\
\hline Mean \pm SD & $442.3 \pm 813.1$ & $306.0 \pm 524.2$ & $234.3 \pm 700.7$ & 0.28 & 0.16 \\
\hline Median & 85.0 & 31.0 & 25.0 & & \\
\hline
\end{tabular}

* Because of rounding, percentages may not total 100.

$\uparrow$ Values obtained at month 9 and month 12 were combined.

costeroids. There were three reports of serum sick- kilogram, and three in the group given $6 \mathrm{mg}$ of naness, one in each group. Only one of these events was accompanied by a change in complement levels, and all three occurred at a single study site. These events complicated fewer than 1 in 250 infusions. Treatment was discontinued because of an adverse event in three patients in the placebo group, When the values obtained at month 9 and month four in the group given $3 \mathrm{mg}$ of natalizumab per 12 were combined, the number of new enhancing 
lesions and scans showing activity were similar in all three groups (Table 2). After treatment, there was no significant difference among the three groups either in the total number of relapses or in those objectively confirmed (Table 3).

\section{I SCUSSION}

Our study provides MRI and clinical evidence that selective inhibition of $\alpha_{4}$ integrin-mediated adhesion and migration of leukocytes is an effective approach to the treatment of multiple sclerosis. The $\alpha_{4}$ integrin-specific humanized monoclonal antibody natalizumab suppressed the formation of gadolinium-enhancing inflammatory brain lesions over the six-month treatment period. This effect was evident one month after the first infusion and was sustained throughout the treatment period. The reduction in the formation of lesions was approximately 90 percent at a dose of both $3 \mathrm{mg}$ per kilogram and $6 \mathrm{mg}$ per kilogram and was thus greater than the reduction of 50 to 80 percent reported with the $\beta$-interferons and the reduction of approximately 30 percent reported with glatiramer acetate. ${ }^{3,22,23}$

Although the intent of our study was not to

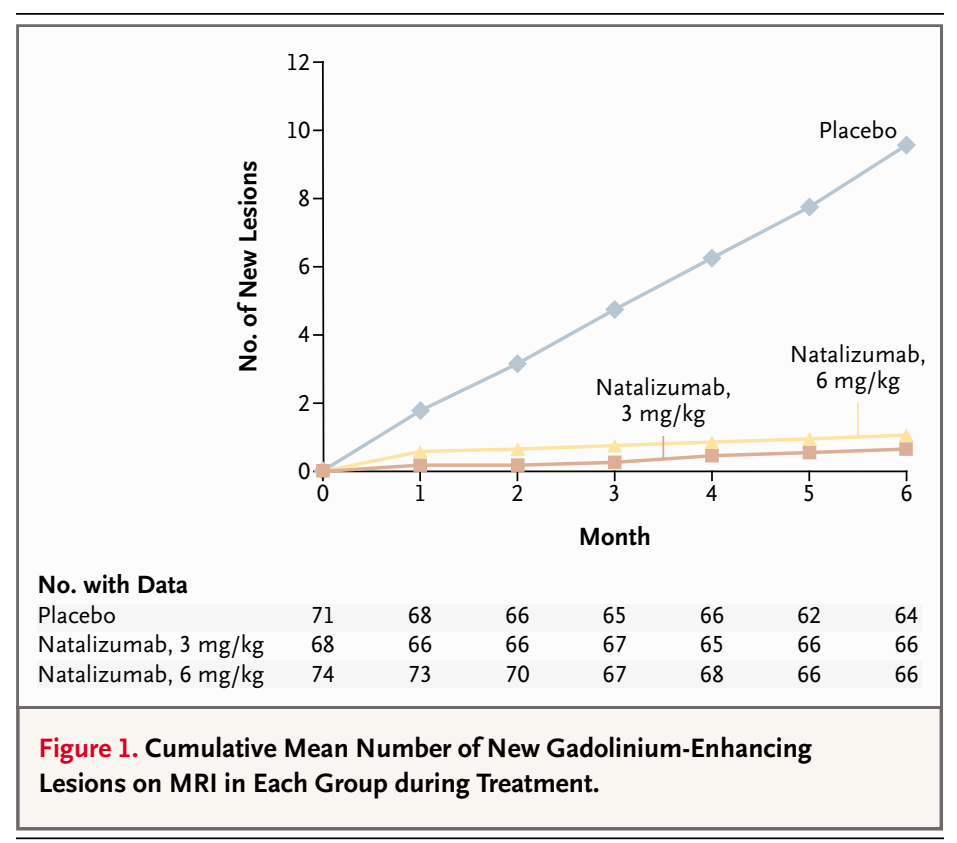

demonstrate that natalizumab affected clinical outcomes, treatment nevertheless resulted in a significant reduction in the frequency of relapse and an increased perception of well-being among the patients. The magnitude of the reduction in both total

\begin{tabular}{|c|c|c|c|c|c|}
\hline \multirow[t]{2}{*}{ Relapses } & \multirow[t]{2}{*}{ Placebo } & \multirow[t]{2}{*}{$\begin{array}{c}3 \mathrm{mg} \text { of } \\
\text { Natalizumab/kg }\end{array}$} & \multirow[t]{2}{*}{$\begin{array}{c}6 \mathrm{mg} \text { of } \\
\text { Natalizumab/kg }\end{array}$} & \multicolumn{2}{|c|}{$P$ Value } \\
\hline & & & & $\begin{array}{l}\text { Placebo vs. } \\
3 \mathrm{mg} \text { of } \\
\text { Natalizumab }\end{array}$ & $\begin{array}{c}\text { Placebo vs. } \\
6 \mathrm{mg} \text { of } \\
\text { Natalizumab }\end{array}$ \\
\hline \multicolumn{6}{|l|}{ During treatment } \\
\hline Total no. of patients & 71 & 68 & 74 & & \\
\hline Total no. of relapses & 36 & 18 & 15 & & \\
\hline No. of objective relapses & 18 & 3 & 8 & & \\
\hline No. of patients with a relapse & 27 & 13 & 14 & 0.02 & 0.02 \\
\hline No. of patients with an objective relapse & 15 & 3 & 8 & 0.004 & 0.11 \\
\hline No. of patients requiring corticosteroid treatment & 22 & 5 & 7 & $<0.001$ & 0.002 \\
\hline \multicolumn{6}{|l|}{ After treatment } \\
\hline Total no. of patients & 69 & 67 & 67 & & \\
\hline Total no. of relapses & 24 & 24 & 26 & & \\
\hline No. of objective relapses & 11 & 10 & 4 & & \\
\hline No. of patients with a relapse & 24 & 21 & 23 & 0.72 & 1.00 \\
\hline No. of patients with an objective relapse & 11 & 8 & 4 & 0.62 & 0.16 \\
\hline
\end{tabular}




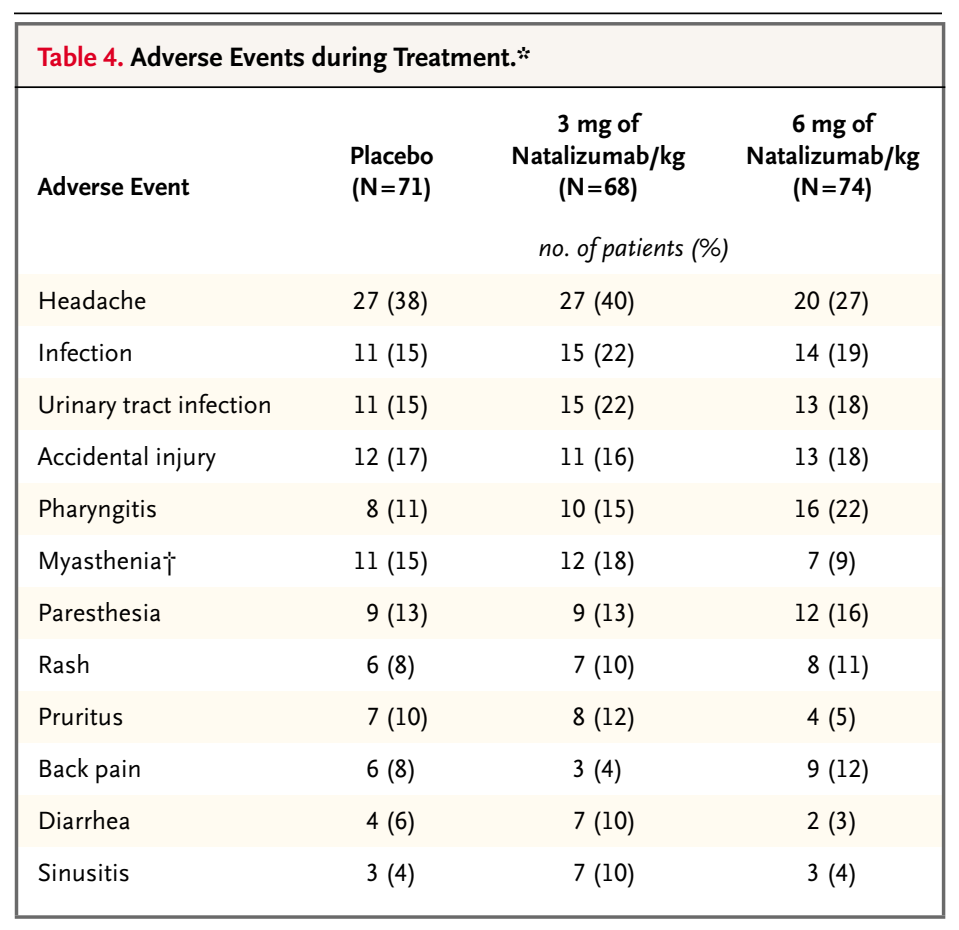

* Adverse events are shown in decreasing order of frequency. The events listed are those that occurred during the treatment period in at least 10 percent of patients and with greater frequency in either natalizumab group than in the placebo group. There were no significant differences among the groups.

$\dagger$ Myasthenia includes weakness and muscle weakness.
Natalizumab binds to $\alpha_{4}$ integrin and is an antagonist of integrin heterodimers containing the $\alpha_{4}$ integrin subunit. One such heterodimer is $\alpha_{4} \beta_{1}$ integrin, which is expressed on the surface of activated lymphocytes and monocytes - cells that have been implicated in the pathogenesis of acute inflammatory lesions and the breakdown of the blood-brain barrier in patients with multiple sclerosis. ${ }^{24,25}$ Our results provide evidence of a role of $\alpha_{4}$ integrin - and the immune cells that express it - in the pathogenesis of acute inflammatory lesions in patients with multiple sclerosis. The increase in circulating lymphocytes in patients treated with natalizumab is consistent with a mechanism involving the antagonism of $\alpha_{4}$ integrin-dependent adhesion of leukocytes that migrate to regions of inflammation. Binding of natalizumab to $\alpha_{4} \beta_{1}$ integrin may also inhibit the activation of $\mathrm{T}$ lymphocytes or eliminate autoreactive $\mathrm{T}$ lymphocytes, and both doses of natalizumab were associated with near-saturation of the $\alpha_{4} \beta_{1}$ integrin receptor. The reduction in the number of new enhancing lesions was evident after one month of treatment, suggesting that natalizumab acts rapidly to prevent the development of lesions.

In summary, natalizumab had beneficial effects on clinical and imaging outcomes in patients with relapsing multiple sclerosis. Therapy was well tolerated during the six-month trial. Promising results with this agent have also been obtained in a randomized controlled trial of patients with Crohn's disease. ${ }^{26}$ Although our results are encouraging, longer-term data are needed. The effect of natalizumab on the progression of disability and its effect in direct comparison with existing therapies are not yet known.

Sponsored by Elan Pharmaceuticals, South San Francisco, California, and Biogen, Cambridge, Mass.

Dr. Miller has reported receiving grant support from Elan, Schering, and Biogen; honorariums for giving expert advice to Biogen, Wyeth, and Bristol-Myers Squibb; and lecture fees from Serono. Dr. Khan has reported receiving grant support or honorariums from Elan, Teva Neuroscience, Biogen, Serono, and Berlex. Dr. Sheremata has reported receiving grant support from Elan, Teva Neuroscience, Serono, and Biogen. Dr. Blumhardt has reported receiving honorariums from Serono, Teva Neuroscience, and Bayer for giving lectures and expert advice. Dr. Rice has reported receiving grant support from Elan and honorariums from Elan for giving expert advice. Dr. O'Connor has reported receiving grant support from Elan, Biogen, Athena Neurosciences, Aventis, Berlex, Serono, Teva Neurosciences, Angiotech, and Amgen. Dr. Dalton has reported receiving salary support from Elan (through a grant held by the Institute of Neurology) to analyze the MRI data. The MRI group at the Institute of Neurology is also supported by the Multiple Sclerosis Society of Great Britain and Northern Ireland.

We are indebted to Drs. Kenneth Johnson, Stephen Donoghue, and Carol Greenlees for their valuable contributions during the conduct of this study; to Dr. Michael Panzara for many helpful sugges- 
tions and enthusiastic support during the preparation of the manu- Charles Davis, Donald Bennett, Frances Lynn, and Minhua Yang for script; to Dr. Alfred Sandrock for helpful comments; and to Dr.

statistical advice and analysis.

APPENDIX

In addition to the authors, the following investigators participated in the International Natalizumab Multiple Sclerosis Trial (principal investigators are in boldface type): Institute of Neurology, London (MRI Analysis Center) — G.J. Barker, D.G. MacManus, C. Webb, C. Middleditch, S. Lewis, T. Pepple, E. Riddle, C. Coombs; University ofCalifornia at Davis, Sacramento - M. Agius, D. Richman, J. Adams, M. Buonocore; University of Nebraska Medical Center, Omaha - J. Al-Omaishi, K. Markopoulou, K. Healey, P. Sorensen; Royal Victoria Infirmary, Newcastle upon Tyne, United Kingdom - D. Bates, J. Forsyth, J. Curlis, P. English; University Hospital Queens Medical Centre, Nottingham, United Kingdom — V. Orpe, T. Jaspen; University of Washington, Seattle - J. Bowen, M. Chang, H. Lew, M. Burke, T. Richards; Mayo Clinic, Scottsdale, Ariz. - J.L. Carter, D. Dodick, J. Takata, M. Malikowski, K. Nelson; Washington University School of Medicine, St. Louis - D.A.H. Cross, J. Trotter, D. Derrington, J. Lauber, C. Martinez, G. Foster, T. Conturo; University of British Columbia, Vancouver, Canada - V. Devonshire, J. Oger, L. Wang, W. Morrison, L. Costley; North Staffordshire Royal Infirmary, Stoke on Trent, United Kingdom - C. Hawkins, C. Mathews, C. Gibson; Hospital for Joint Diseases, New York-J. Hebert, I. Rozentsvit, L. Capolino, J.P. Kelly; Carolinas Medical Center, Charlotte, N.C. - M. Kaufman, S. Putman, A. Diedrich, R. Follmer, S. Dombrowski, C. Graves, B. Harwick; Wayne State University, Detroit - A.C. Tselis, M. Din, C. Caon, M. Cochran, Z. Latif, R.P. Lisak, M. Zvartau-Hinds; Foothills Hospital, Calgary, Alta., Canada - L. Metz, J. Scott, D. Patry, M. Yeung, J. Heuser, C. Wallace, S. Curtis; Maimonides Medical Center, Brooklyn, N.Y. - A. Miller, E. Drexler, M.J. Keilson, K. Bruining, A. Schneider, R. Wolintz, L. Sciarra, H. Oltazewska; Rocky Mountain Multiple Sclerosis Center, Englewood, Colo. - R.S. Murray, A. Bowling, R.E. Kramer, K. Bracht, C. O’Brien, L. Seeberger, J. Leitch, E. Prenger, R. Gagnon; St. Michael's Hospital, Toronto - M. Hohol, T. Gray, E. Viara, B. Gray, L. Lewin, J. Rainford; Radcliffe Infirmary, Oxford, United Kingdom — J. Palace, A. Cavey, V. Moody; Texas Neurology, Dallas - J.T. Phillips, A. Martin, D. Hietzman, S. O'Leary, J. Phillips, M. Newsome; Lehigh Valley Hospital, Allentown, Pa. - A. Rae-Grant, J.E. Castaldo, G. Mackin, N.J. Eckert, E. Shoemaker, L. Fowler-Blatt; University ofChicago, Chicago - A. Reder, B. Arnason, A. Noronha, P. Manning, V. Edmonds, B. Jamison, R. Ladsaria; London Health Science Center, London, Ont., Canada - P. Mandalfino, D. Wingerchuk, M. Nicolle, M. Hopkins, D. Lee, E. Buchner, K. Kennedy; Guy's Hospital, London - M. Sharief, K. Wilson, S. Soudain, J. Bingham, P. Graves; University of Miami School of Medicine, Miami - A. Minegar, M. Martinez, G. Calabro, S. Falcone; Ninewells Hospital, Dundee, United Kingdom - R. Swingler, S. Wilson, W. Milne; Yale University School of Medicine, New Haven, Conn. - T. Vollmer, M.A. Rizzo, M. Carrithers, G. Blonco, H. Sarofin; Walton Centre for Neurology and Neurosurgery, Liverpool, United Kingdom - C. Young, L. Owens, C. Dickinson.

REFERENCES

1. Compston DAS, Matthews WB McDonald WI, Ebers G, Wekerle H, Lass mann H. McAlpine's multiple sclerosis. 3rd ed. Edinburgh, Scotland: Churchill Livingstone, 1998.

2. IFNB Multiple Sclerosis Study Group and the University of British Columbi MS/MRI Analysis Group. Interferon beta-1b in the treatment of multiple sclerosis: fina outcome of the randomized controlled trial. Neurology 1995;45:1277-85.

3. Jacobs LD, Cookfair DL, Rudick RA, et al. Intramuscular interferon beta-1a for disease progression in relapsing multiple sclerosis. Ann Neurol 1996;39:285-94. [Erratum, Ann Neurol 1996;40:480.]

4. Prevention of Relapses and Disability by Interferon Beta-1a Subcutaneously in Multiple Sclerosis Study Group. Randomised double-blind placebo-controlled study of inter feron beta-1a in relapsing/remitting multiple sclerosis. Lancet 1998;352:1498-504. [Erratum, Lancet 1999;353:678.]

5. Johnson KP, Brooks BR, Cohen JA, et al. Copolymer 1 reduces relapse rate and improves disability in relapsing-remitting multiple sclerosis: results of a phase III multicenter, double-blind placebo-controlled trial. Neurology 1995;45:1268-76.

6. Hynes RO. Integrins: a family of cell surface receptors. Cell 1987;48:549-54.

7. Frenette PS, Wagner DD. Adhesion molecules — part I. N Engl J Med 1996;334: 1526-9.

8. Idem. Adhesion molecules - part II: blood vessels and blood cells. N Engl J Med 1996;335:43-5.

9. Thompson AJ, Kermode AG, Wicks D, et al. Major differences in the dynamics of primary and secondary progressive multiple sclerosis. Ann Neurol 1991;29:53-62.
10. Harris JO, FrankJA, Patronas N, McFarlin DE, McFarland HF. Serial gadolinium enhanced magnetic resonance imaging scans in patients with early, relapsing-remit ting multiple sclerosis: implications for clinical trials and natural history. Ann Neurol 1991;29:548-55.

11. Thompson AJ, Miller D, Youl B, et al. Serial gadolinium-enhanced MRI in relapsing/remitting multiple sclerosis of varying disease duration. Neurology 1992;42:60-3.

12. Barkhof F, Valk J, Hommes OR, Scheltens P, Nauta JJ. Gadopentetate dimeglumine enhancement of multiple sclerosis lesions on long TR spin-echo images at 0.6 T. AJNR Am J Neuroradiol 1992;13:1257-9.

3. Yednock TA, Cannon C, Fritz LC, Sanchez-Madrid F, Steinman L, Karin N. Prevention of experimental autoimmune encephalomyelitis by antibodies agains alpha 4 beta 1 integrin. Nature 1992;356:636.

4. Kent SJ, Karlik SJ, Cannon C, et al. monoclonal antibody to alpha 4 integrin suppresses and reverses active experimenta allergic encephalomyelitis. J Neuroimmunol 1995;58:1-10.

15. Kent S, Karlik S, Rice GPA, Horner H. A monoclonal antibody to alpha-4 integrin reverses the MRI detectable signs of experimental allergic encephalomyelitis in the guinea pig. Proc Int Soc Magn Reson Imaging 1994;3:1400.

16. Tubridy N, Behan PO, Capildeo R, et al. The effect of anti-alpha4 integrin antibody on brain lesion activity in MS. Neurology 1999;53:466-72.

17. Poser CM, Paty DW, Scheinberg L, et al. New diagnostic criteria for multiple sclerosis: guidelines for research protocols. Ann Neurol 1983;13:227-31.
18. Lublin FD, Reingold SC. Defining the clinical course of multiple sclerosis: results of an international survey. Neurology 1996 46:907-11.

19. Kurtzke JF. Rating neurologic impairment in multiple sclerosis: an expanded disability status scale (EDSS). Neurology 1983 33:1444-52.

20. Grimaud J, Lai M, Thorpe J, et al. Quantification of MRI lesion load in multiple sclerosis: a comparison of three computerassisted techniques. Magn Reson Imaging 1996;14:495-505.

21. Noether GE. Sample size determination for some common nonparametric tests. J Am Stat Assoc 1987;82:645-7.

2. Li DKB, Paty DW. Magnetic resonance imaging results of the PRISMS trial: a randomized, double-blind, placebo-controlled study of interferon-beta1a in relapsingremitting multiple sclerosis. Ann Neurol 1999;46:197-206.

23. Comi G, Filippi M, Wolinsky JS. European/Canadian multicenter, double-blind, randomized, placebo-controlled study of the effects of glatiramer acetate on magnetic resonance imaging-measured disease activity and burden in patients with relapsing multiple sclerosis. Ann Neurol 2001;49:290-7.

24. Coles AJ, Wing MG, Molyneux P, et al. Monoclonal antibody treatment exposes three mechanisms underlying the clinical course of multiple sclerosis. Ann Neurol 1999;46:296-304.

25. Adams CWM. A colour atlas of multiple sclerosis and other myelin disorders. London: Wolfe Medical, 1989.

26. Ghosh S, Goldin E, Gordon FH, et al Natalizumab for active Crohn's disease. N Engl J Med 2003;348:24-32.

Copyright (c) 2003 Massachusetts Medical Society. 